\title{
Financing food system transformation: insights from global climate projects
}

\author{
Abrar Chaudhury and Saher Hasnain
}

Abstract: Climate change poses unprecedented and complex challenges to global food systems. Critical vulnerabilities, continuing inequalities, and unsustainability have demonstrated that food systems need significant intervention in order to deliver safe, just, and healthy food for all, against the backdrop of a changing climate. Innovative interventions and effective financing are needed across the food system to achieve these grand ambitions. While there is recognition of a systems approach in the face of complex issues such as climate change, interventions and financing mechanisms have historically focused narrowly on production or specific sectors within food and related systems. Given the diverse array of stresses and shocks, this approach will not achieve the desired paradigm shifts necessary to secure global food systems and meet the Paris Agreement climate targets. Through a comprehensive review of projects funded through the Green Climate Fund (GCF), this paper shows that paradigm shifting interventions can benefit from a food systems perspective by moving beyond specific sectors and activities and delivering outcomes across the socio-economic and environmental spheres. Climate change and food system challenges are complex and necessitate system approaches, and financing instruments need to be designed and structured with systemic complexity in mind.

Keywords: Food system, climate finance, Green Climate Fund, climate change, systems approach.

Notes on the authors: see end of the article.

(C) The author(s) 2021. This is an open access article licensed under a

Creative Commons Attribution-NonCommercial-NoDerivs 4.0 Unported License 


\section{Introduction}

Climate change poses a huge threat to our global food system. For developing countries, it is an existential crisis as they not only have to feed their growing vulnerable populations but also rely on the sector for livelihoods and generating economic development. The COVID-19 pandemic is exacerbating many vulnerabilities and inequalities in the global food system. Climate disasters, for example, continue while COVID-19 spreads globally. Support for climate-vulnerable farmers in developing countries has improved (World Bank 2021), but lockdown and trade restrictions have hampered access to labour and markets. COVID-19 restrictions impeded the movement of labour, changed consumption demands, closed off processing facilities leading to restrictive distribution and trade policies, with financial pressures across supply systems (UNCTAD 2020). These indicate that vulnerabilities exist along supply chains and in the food system beyond the activity of production. The increasing complexity and fragility of supply chains to climatic and other shocks have necessitated an overarching perspective of the whole system.

Food systems consist of all activities associated with food production, such as producing, processing, retailing, transporting, consuming, and disposing (CIAT 2017, Woodhill et al. 2020). The range of food system activities are estimated to be responsible for 26 per cent of global GHG (greenhouse gas) emissions every year, of which crop production itself makes up only 27 per cent (Poore \& Nemecek 2018). While food system thinking and research have been conducted over many decades, ${ }^{1}$ their findings are often not integrated into food and climate-related issues. In addition, most transformation approaches in developing economies, thus far, have tended to focus primarily on smallholders and food production (IFAD 2013, CFS 2016, Woodhill et al. 2020). While attention on production and small-scale farmers is important, they are part of a bigger picture that is undergoing significant transformation, influenced by demographic change, resource degradation, and climate change. Opportunities for stakeholders within the production sector need to be considered in this wider context, particularly given the increasingly unhealthy, unsustainable, and inequitable outcomes of our food systems.

Extreme climate events continue to destroy farmer livelihoods and food security across the world and, in combination with the pandemic, there is a serious risk of hunger and famine for years to come (Mbow et al. 2019). Lockdowns have led to the closure of local markets on which smallholder farmers and small food producers are

\footnotetext{
${ }^{1}$ Notable examples are the works by United Nations Environment Programme's (UNEP) International Resources Panel on the impacts of food system activities on the natural environment (2016) and studies by the University of London's Centre for Food Policy (Lang \& Barling 2012, Parsons et al. 2019).
} 
so reliant. Tonnes of food remain unharvested on fields if migrant labourers cannot travel, and surplus livestock is being buried (Marchant-Forde \& Boyle 2020, Stephens et al. 2020, FAO, 2021). Informal economies on which smallholders and small producers depend for survival suffer. Small producers going out of business might also pave the way for bigger businesses, further consolidating and concentrating power in agriculture and broader food systems through integrated supply chains (Kwak 2020). These actors and their associated activities are all interconnected. 'Core' food system activities are influenced by drivers within social, political, economic, environmental, and natural realms (Van Berkum et al. 2018, Ingram \& Zurek 2018), and supported by processes such as regulations, standards, communications, and logistics. These activities profoundly affect food and nutrition security, environmental sustainability, and social and economic well-being (HLPE 2017). Conceptualising the food system in this manner helps identify the connections and relationships between the wide range of activities and explore the multiple dimensions and systems that food interacts with (for example, environment, socio-economic, and health), the actors carrying out the activities (for example, producing, distributing, and storing), and the drivers that affect them (for example, urbanisation, technology, and climate change). Such an approach enables identification of interventions and the analysis of their unintended and indirect consequences.

In this article we analyse projects funded by the Green Climate Fund (GCF) to understand the role of climate finance in the context of food system activities. GCF is an operating entity of the financial mechanism of the United Nations Framework Convention on Climate Change (UNFCCC) and serves the 2015 Paris Agreement, supporting the goal of keeping average global temperature rise well below $2^{\circ} \mathrm{C}$. GCF partners with intermediaries (known as Accredited Entities) work alongside developing countries to conceive project ideas and submit funding proposals to the GCF. As the largest dedicated public sector climate fund for developing countries, GCF offers an ideal setting for studying the role of finance in helping developing countries transition to a low-emission and climate-resilient food system. Applying a food system approach to the GCF portfolio is timely as its funding for climate themes, including food, is committed to increase greatly in coming years from its current US $\$ 10$ billion portfolio. Identifying the necessary frames, measures, and standards at this stage of the process will help guide food system transformation with incoming investments, especially the transformational aspects of finance in food and how funding for projects and programmes can transform the entire sector beyond a single project.

Climate finance offers an important opportunity through funding low-carbon and climate-resilient actions in the food system of developing countries (Millan et al. 2019). The food sector's vulnerability to climate and market shocks has traditionally kept funding mechanisms at bay (UNEP 2016). However, by developing innovative 
concessional and blended climate financing products, funding institutions are now attracting project developers to the food sector and broader adaptation activities. Despite progress, access to long-term and reliable climate finance remains a challenge, even for small-scale agriculture, despite emphasis on economic development and poverty alleviation activities (FAO 2012, Chiriac et al. 2020). Available funding often takes a narrow project and programmatic approach to food systems, focusing on particular aspects and activities, notably production (Diaz-Bonilla 2018, Conevska et al. 2019). For example, production-oriented funding projects may support improved farming practices for procuring high-yield seeds or investments in water harvesting techniques, without explicitly accounting for the broader outcomes. However, financing alone cannot solve the food challenge, and particular financing mechanisms may actually increase farmer vulnerability through input-focused loans at times of crop failure. Research indicates that financial resources have to be supported by the appropriate knowledge to apply interventions effectively (Chaudhury et al. 2017) and without appropriate risk-mitigating support such as insurance and grants, farmers will not necessarily adopt the most profitable measures to improve livelihoods (Hazell et al. 1986, Chaudhury et al. 2016). A system-based approach is needed to understand farmer needs in the context of the food system to generate robust strategies.

For example, the products of climate-resilient methods may still be processed and transported by high-emission means, thereby reducing the downstream environmental, food security, and socio-economic benefits of the whole process. The lack of a systems approach in finance suggests that funders and policymakers can underestimate or miss the catalytic nature of finance in the transition to a low-emission and climate-resilient food system (Nakhooda et al. 2014, Palmer 2016, Nghiem et al. 2018). While many countries identify sustainable agriculture in their global and national commitments and plans, few set goals beyond production in certain parts of the food system, such as sustainable consumption, processing, transportation and logistics, and food waste (UNFCCC 2021). Opportunities for reducing the food systems emissions profile and increasing its climate resilience beyond production remain untapped and poorly defined. Countries lack tangible incentives and mechanisms to address climate problems without measurable commitments related to the food system. As the food system is highly complex and dynamic, with different drivers, outcomes, and stakeholder perspectives, it is important to explore how financing solutions can be applied in a systematic manner.

This article addresses an important gap between the aspiration of current climate financing mechanisms on food system transformation and the how food projects are actually funded. This is accomplished by exploring GCF's areas of focus in projects that seek improvements in food system outcomes and how food system thinking is conceptualised. The paper will demonstrate that significant gains in emissions reduction, 
livelihood improvement, number of lives impacted, and food and nutrition security are possible if climate financing mechanisms like the GCF take a food system approach.

This article is organised as follows: an overview of the food system approach is followed by the methods employed, and the analysis of the GCF-funded food projects. The paper concludes with a discussion on the results and significance to current debates in food systems, transformational change, and climate financing.

\section{The food systems approach}

Global emissions are currently at 50 billion tonnes of $\mathrm{GHG}$ per year in $\mathrm{CO}_{2}$ equivalents. Emissions reduction is often considered primarily in the realm of energy use and transport. However, the global food system is responsible for nearly 26 per cent of global GHG emissions, and pathways to emission reduction are not clear. Within the food system, livestock and fisheries account for 31 per cent of food system emissions, crop production accounts for 27 per cent, land use for 24 per cent, and supply chains for 18 per cent (Poore \& Nemecek 2018). A further 24\% of the total emissions from global food systems come from food wasted and lost through supply chains and by consumers (Poore \& Nemecek 2018). This demonstrates that the various activities within the food system all consume natural resources and energy.

Beyond emissions, livelihoods are a critical concern. The food system currently employs large numbers of people in developing countries. This includes employment in agriculture, processing, storage, distribution, transport, logistics, retailing, and other services (Townsend et al. 2017). For example, while farming accounts for about 65 per cent of total employment in low-income countries (Castaneda et al. 2016), the food and beverage sector accounts for 40 per cent of employment in manufacturing in Malawi and Tanzania. Even in developed countries, a significant portion of employment takes place in the food system. For example, in Great Britain, 13 per cent of the population was employed in food system activities in 2019, which includes agriculture and fishing, food and drink manufacturing, wholesaling, retailing, and catering (National Statistics 2019). World Bank analysis reveals that by 2025, the food system will be responsible for more than 70 per cent of all employment in Ethiopia, Malawi, Mozambique, Tanzania, Uganda, and Zambia (Townsend et al. 2017). Discussions of livelihoods and living income therefore become essential, particularly since a significant proportion of food system actors (for example, small-scale farmers) do not earn enough for decent housing, education, food, and healthcare (Gneiting \& Sonenshine 2018). However, improvements in food system activities may not necessarily translate into improvements in livelihoods. For example, controlled-environment agriculture techniques may reduce labour-intensive jobs that many people rely on. Therefore, 
most GCF food projects take a co-development approach to food and livelihood to avoid perverse trade-offs. Food system interventions through GCF projects can achieve co-benefits in the environmental and socio-economic spheres by improving the livelihoods of the millions of people employed within it.

The challenges facing global food systems are multidimensional, complex, intractable, and contested. Climate change, food security, environmental degradation, and the dynamics between humans and animal health are examples of wicked problems (Lazarus 2008, Etzion et al. 2017). Reductionist approaches to such problems might result in the exclusion of certain necessary stakeholders, interdependencies overlooked, and targeting symptoms instead of the problem itself. Systems thinking is a way of approaching and addressing such problems. Taking a systems approach provides structures for dealing with the connections between problems. Systems thinking necessitates a different approach to complex problems, by exploring not just what is known about each, but also interrogating and reflecting on the processes of knowledge, biases, barriers, and connections. Reflection, iteration, boundary judgements, and interdisciplinary collaborations are therefore key in systems thinking. These processes can help ensure that multiple differing perspectives are included, the situation is viewed in the longer term, and consideration given to the systemic consequences of interventions (Meadows 2008). Systems thinking encourages the shift from narrow and targeted analyses to those that incorporate all perspectives and unintended consequences, and work with the dynamic relationships embedded in complex systems.

Systems thinking must be applied to food challenges because of the need for structured, inclusive, iterative, and systematic approaches. Mapping the 'big picture' of food commodities or challenges allows for the exploration of the many challenges and opportunities available in a methodological and structured way (Ingram 2011). Figure 1 shows the food system framing developed by the Foresight4Food Initiative that integrates key systems concepts from Ingram and Zurek (2018) and 'Making Markets work for the Poor' (Springfield Centre 2015).

A food system includes the connected and interdependent set of institutions, organisations, and enterprises, cultural rules and norms, activities and relationships that govern, develop, and deliver the inputs to food production activities and handle, process, transport, store, and retail the products to consumers and eventually to waste managers. The industry and business actors, for instance, interact and play an important role in linking smallholder farmers to the food system through input supply, procurement, markets, and financial support. A food system has multiple outcomes across the socio-economic and environmental spheres, with frequent trade-offs being made across desired goals. A food system approach helps identify these goals and outcomes and shapes the strategies needed to achieve gains across all spheres and maximise synergies. This framing is useful for examining the interrelationships 


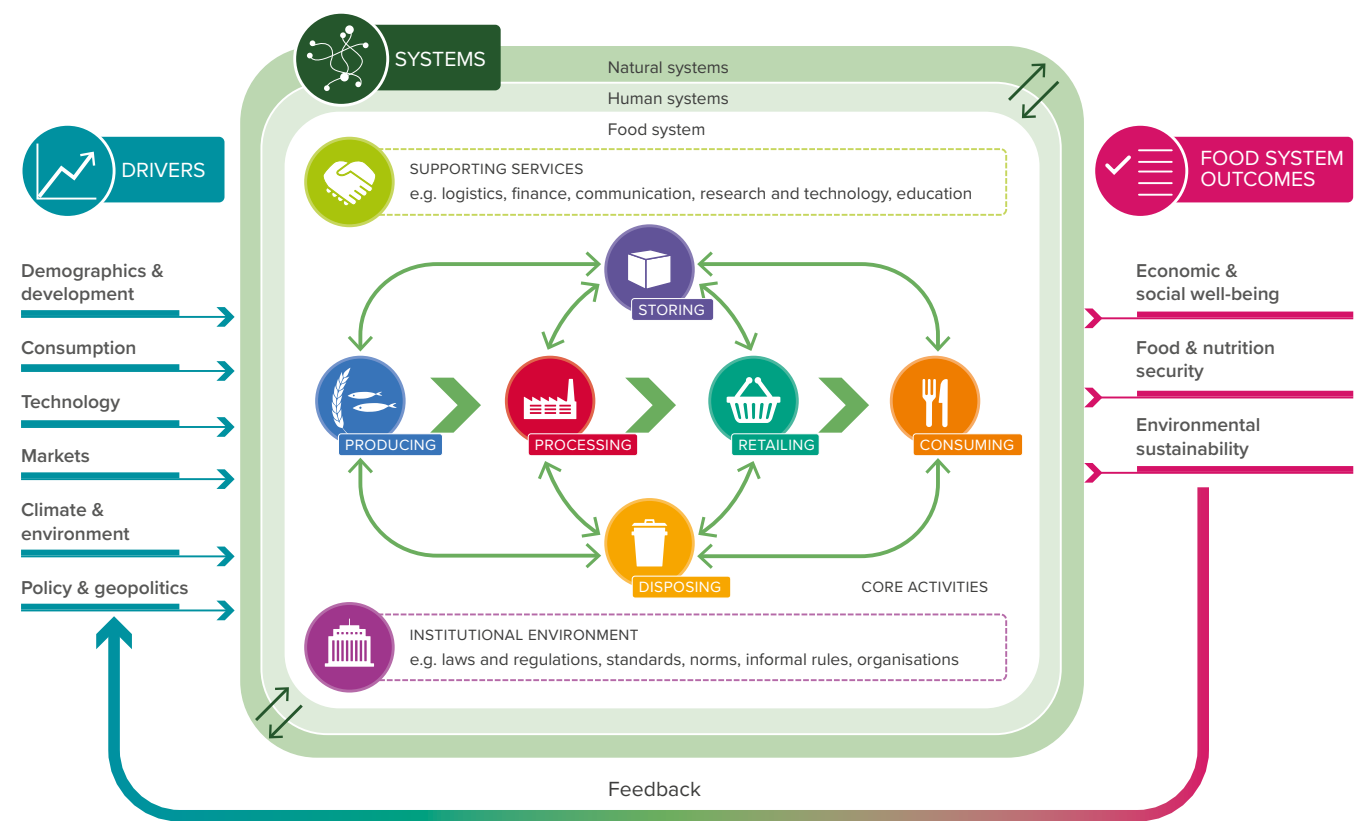

Figure 1. Foresight4Food food systems model describing food system activities, drivers, and feedback loops (Woodhill et al. 2020).

between food system activities, outcomes, and the supporting services and activities that enable the system's functioning.

The approach has gained traction in recent years, with the UN Food Systems Summit 2021 acknowledging the fragmentation and lack of clarity in how the concept is realised and operationalised. Important examples of food system approaches in research and practice have been developed by the Global Environmental Change and Food Systems (GECAFs) project (Ingram 2011), Metrics, Models and Foresight for European SUStainable Food And Nutrition, or SUSFANs (Zurek et al. 2018), TRANSMANGO (Brunori et al. 2015), University of London's Centre for Food Policy, the UK Mapping of Food Systems (Hasnain et al. 2020), Resilience of the UK Food System in a Global Context project (GFS 2020), and RAND Europe's food system map for the UK's Food Standards Agency (FSA) (Smith et al. 2019). Such maps are part of a systematic inquiry of the distinctions, systems, relationships, and perspectives of the system of concern (Cabrera et al. 2008).

The goals of GCF-funded projects are organised around driving a paradigm shift related to the Sustainable Development Goals (SDGs) and meeting the commitments of the parties under the 2015 Paris Agreement. The GCF initial investment framework defines paradigm shift potential as the "the degree to which the proposed activity can catalyse impact beyond a one-off project or programme investment' (GCF 2020: 3). The assessment dimensions within this framework focus on scale, replicability, and 
sustainability of the funding. However, due to the programmatic nature of many such projects, the interventions are tightly focused on limited activities of the food system, and the paradigm criteria are applied in a limited way. This becomes a stumbling block towards not only developing a resilient food system, but also making progress towards all the SDGs and the Paris Agreement for transformational change.

\section{The analytical framework}

This paper proposes an analytical framework, as shown in Table 1, based on three key principles arising from the food systems approach discussed before to evaluate the systems and finance capability of the GCF projects:

1. Activities of the food system result in 'outcomes' that can be categorised into economic and social well-being, food and nutrition security, and environmental sustainability. These are part of the paper's analytical framework to explore the breadth of the GCF projects' anticipated paradigm shift.

2. Food system activities are present at the core of the food system. Carried out by a diverse array of actors, a food system can consist of various interacting food system activities.

a. Production activities include, but are not limited to, farming, livestock rearing, aquaculture, fishing, foraging, and hunting. For the purposes of this classification, this category includes pre-production activities, such as developing agricultural chemicals, fertilisers, and farm machinery.

b. Aggregation consists of bringing produce and products from different sources together for improving supply chain regularity: for example, the coordination of produce from multiple suppliers for large retailers and wholesale service providers (Dillemuth \& Hodgson 2016).

c. Processing (and/or manufacturing) includes basic or primary processing, such as washing and trimming, and value-addition activities, such as confectionary production (Hasnain et al. 2020).

d. Distribution moves products between the various sites and facilities in the food system.

e. Retailing consists of activities related to the sale of products to consumers, in sites such as, but not limited to, supermarkets.

f. Consumption consist of activities for offering a balanced and nutritious diet

g. Food disposal activities consist of the disposal and processing of degraded, inedible, and wasted food sent to food waste destinations, such as landfills (WRAP 2020). 
Table 1. Analytical framework on three key principles arising from the food systems approach to evaluate the systems and finance capability of GCF projects.

\begin{tabular}{lll}
\hline Food system outcomes & Food system activities & $\begin{array}{l}\text { Supporting mechanisms and } \\
\text { institutions }\end{array}$ \\
\hline 1. Economic and social well-being & 1. Production & 1. Industry and business \\
2. Food and nutrition security & 2. Storage and aggregation & 2. Infrastructure \\
3. Environmental sustainability & 3. Processing & 3. Policy and regulations \\
& 4. Distribution & \\
& 5. Retail & \\
& 6. Consumption & \\
& 7. Disposal & \\
\hline
\end{tabular}

3. These food system activities and actors are influenced by a range of supporting governance mechanisms and institutions. For the purposes of this paper, these are categorised into industry and business (for example, SMEs (small and mediumsized enterprises), multinationals, civil society, public actors), infrastructure (physical and institutional), and policy and regulations including public sector engagement.

\section{Methods}

The research for this paper combined a quantitative analysis of projects funded by GCF under the results area of 'health, food, and water security' with a qualitative analysis (King et al. 1994, Silverman 2005) of semi-structured interviews with experts and entities involved in developing and implementing GCF projects in a mixed methods approach (Johnson et al. 2007). Health, food, and water security is part of the climate adaptation theme and one of the eight result areas prioritised by GCF for funding projects under climate mitigation and adaptation It is often challenging to separate out the climate-related aspects of impacts on health, well-being, and water and food security. However, the interconnected nature of the challenge means that the GCF has a range of potential entry points to focus on for transformational outcomes of food systems. We selected projects that explicitly focused on food as one of their main objectives.

We collated the project data from the GCF website ${ }^{2}$ that lists all projects approved under eight climate action areas, categorised under the themes of climate change mitigation and adaptation. Of the 177 projects approved by the GCF board ${ }^{3}$ for funding,

\footnotetext{
${ }^{2} \mathrm{https}: / / \mathrm{www}$.greenclimate.fund

${ }^{3}$ Approved projects up to the 29th Board Meeting.
} 
seventy-five projects fall under the health, food, and water security action area, representing a total project funding of US $\$ 827$ million out of the US\$8.9 billion committed for all projects. The action area represents 42 per cent of all approved projects, but only 9 per cent of the total funding committed. Of the seventy-five projects, we selected fifty-six projects that explicitly identified food (or other aspects of the food system) in their project objectives, and food action area represented at least 10 per cent of the total project value. Of the fifty-six projects, nine are implemented by direct national entities, two by direct regional entities, and forty five by international entities.

We reviewed the approved funding proposal of each selected project, which are publicly available on the GCF website. Within each funding proposal, we read the programme description and the investment criteria to identify and code the specific outcomes, activities, and mechanism of the project within the food system (Saldaña 2021). We mapped each project's objectives and activities to the three key principles arising from the food systems approach described in the analytical framework: namely, (1) food system outcomes, (2) food system activities, and (3) institutions and governance mechanisms.

\section{Results and analysis}

We present the results from the review of the GCF-funded projects under the food results area, based on the three key principles of food system discussed in Table 1. We follow this with an analysis of the project structures and implementation approach of the projects to understand the challenges and opportunities for adopting a systems approach to funding.

\section{Food system analysis}

\section{Food system outcomes}

Our analysis of the GCF food projects reveals that all fifty-six projects have explicitly considered the key outcomes of achieving food and nutrition security, improving socio-economic status, and safeguarding environmental resources under the sustainability category. Given the GCF's core criteria for transformational change, this is expected. The GCF has set explicit guidelines for all adaptation projects to identify the number of lives impacted. For projects to qualify under the food result area, these must show clear objectives for enhancing food security, although the nutrition impact is not always stated in all projects. Finally, projects have to clearly demonstrate a 
strong climate rationale for their interventions in the funding proposals and how the projects will deal with these challenges to succeed in securing funding. Our analysis is limited to projects that have been successfully funded based on the intended outcomes and not the actual outcomes delivered, as all projects are currently in approval or implementation phases. These projects need to demonstrate a strong climate rationale and meet the investment requirements to qualify for funding. Analysing the actual outcomes of the projects on their completion will be necessary to understand the transformational impact of GCF funding. Information on projects that fall short on the climate rationale and investment criteria is not available. According to the GCF team, unfunded projects continue in the project cycle until all objections raised in the evaluation process are addressed or the project developers stop pursuing the funding proposals. Despite this limitation, given the GCF process, we can assume that approved and funded projects incorporate food system outcomes. This focus on achieving food system outcomes strengthens the awareness and desire of GCF in addressing transformational change across many activities at the heart of food systems and across society, economy, health and well-being, and the environment. It demonstrates a strong understanding by GCF that these are interlinked problems requiring systemic solutions and transformation in how our food systems operate. However, this systemic approach has yet to translate consistently across the project portfolio in how food system interventions are designed. We discuss these aspects in more detail in the following sections.

\section{Food system activities}

As we move from the broader food system outcomes to a granular analysis of the food system activities, the projects display varying degrees of alignment with the activities. As discussed in the earlier section, food system covers several interrelated activities from food production to consumption, with each activity sensitive to the impacts of climate change but also significantly contributing to GHG emissions.

Our analysis of the GCF projects highlights that the GCF funding is heavily skewed towards production. We observe that the majority of funding projects are designed to improve the resilience of farmers to produce more against the backdrop of a changing climate. Figures 2 and 3 demonstrate that, while all surveyed projects address food production, very few projects consider/include processing (30 per cent), distribution (16 per cent), consumption ( 5 per cent) or disposal (10 per cent) activities of the food system. None of these projects considered retailing activities explicitly. Only two projects address six activity areas of the food system as shown in Figure 4. These are important activities for building a robust and resilient food system and present an opportunity for leveraging climate finance to unlock investments in the 


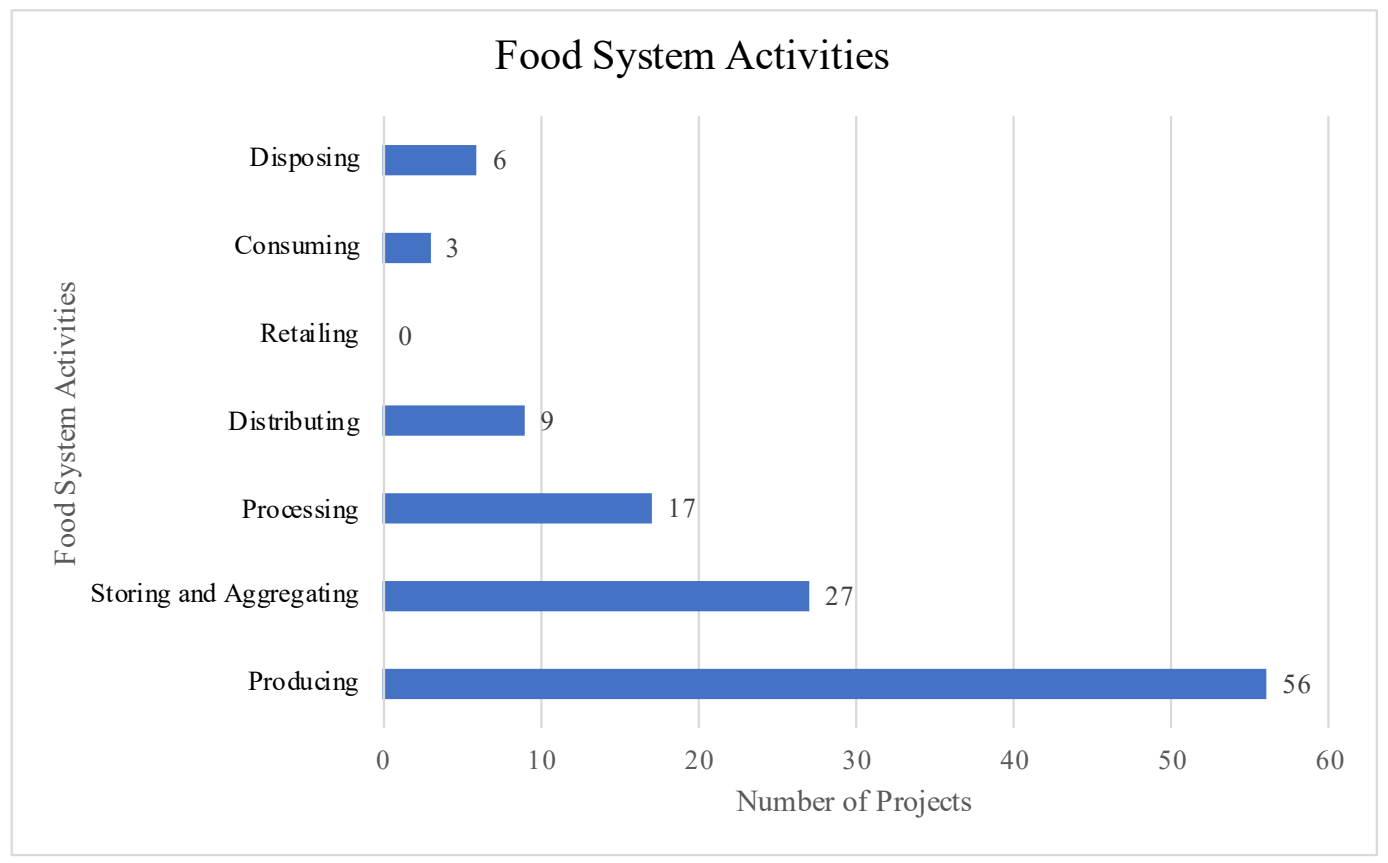

Figure 2. Food system activities in fifty-six GCF-funded projects.

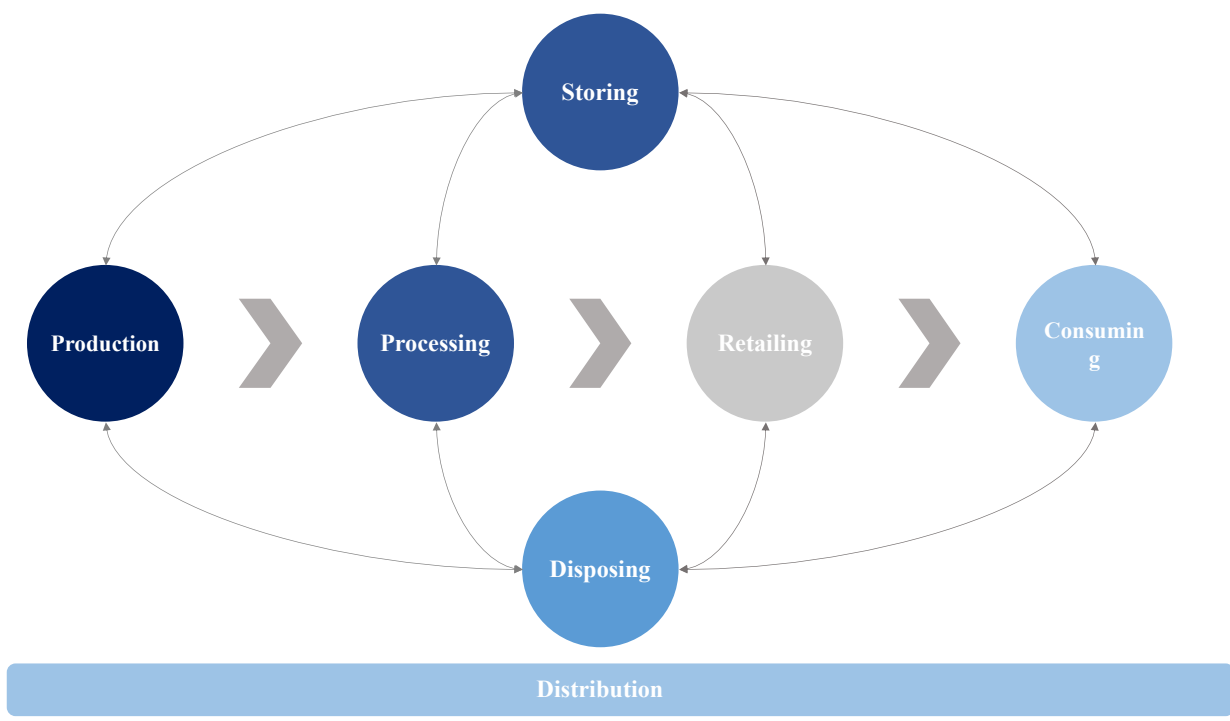

\section{Color Key}

More than $90 \%$ of projects
More than $30 \%$ of projects
More than $10 \%$ of projects
Less than $10 \%$ of projects

Figure 3. Number of GCF projects in the food system theme. 


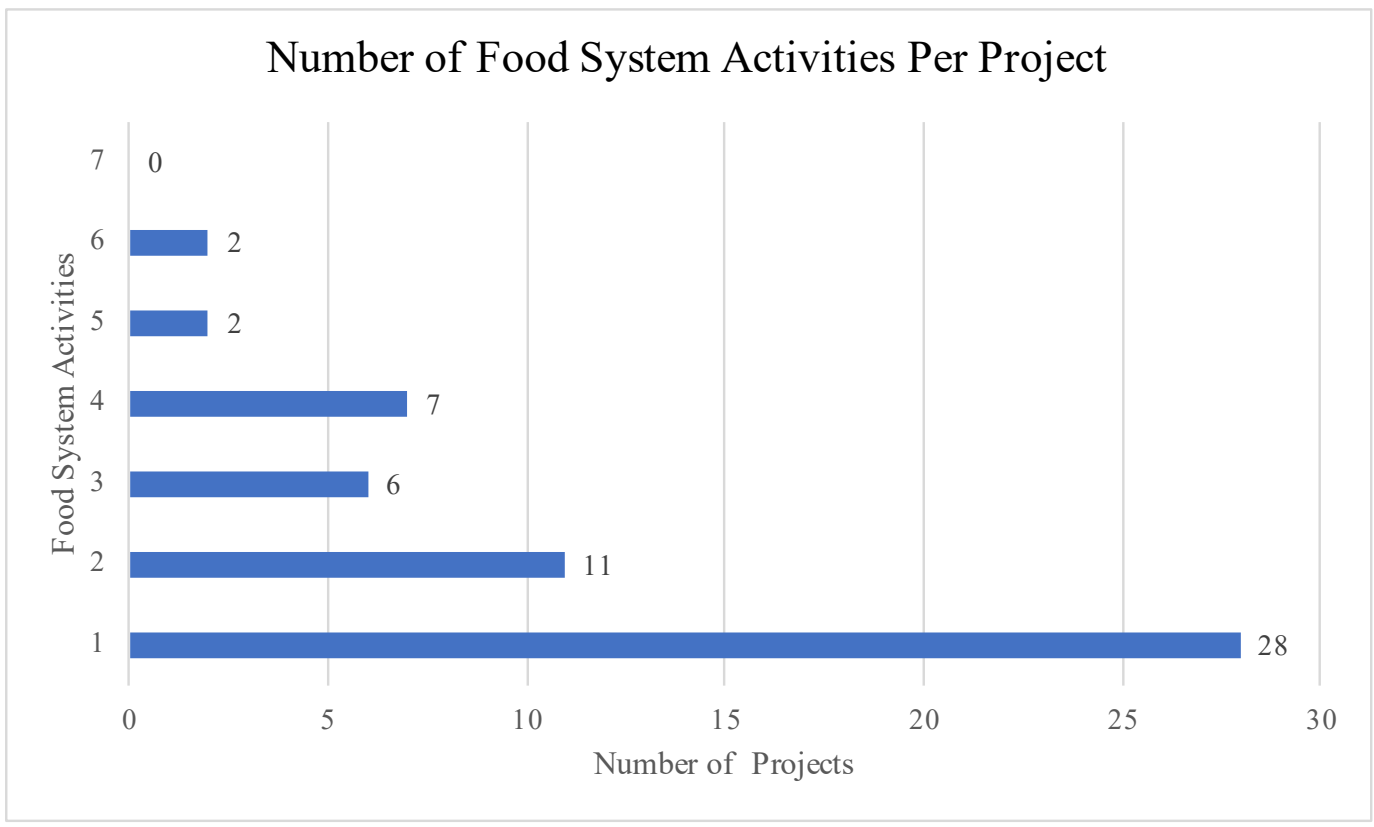

Figure 4. Number of food system activities explicitly addressed in GCF projects.

supply chain. One reason for this production-centric approach is that GCF's investment criteria demand that projects demonstrate a strong climate rationale and the number of lives impacted for the interventions. But GCF leaves it to the project developers to design the interventions based on local needs. Many projects take a localised approach of offering benefits to local communities to meet the GCF requirements, but do not consider the wider opportunities and implications beyond the local communities to the food system activities. This naturally draws the attention of the project developers to the production activity within the food system as it has the potential for the highest number of lives impacted. The number of impacted lives falls along the value chain, as it requires fewer personnel in those areas, and hence is not very attractive for inclusion. A recent report by Worldwide Fund for Nature (WWF) - 'Driven to Waste: Global Food Loss on Farms'- highlights that an estimated 2.5 billion tonnes or 40 per cent of all the food grown goes uneaten around the world each year (WWF 2021). Without taking a systems-wide view for food projects, much of the benefit accrued to the farmers in increased production is lost in other parts of the food system if associated activities in the system are not included. This is important not only for the lost opportunity for addressing the transformational impacts of the proposed activities across the whole system, and given that 18 per cent of GHG emissions is coming from supply chains (Poore \& Nemecek 2018), critical action is missed. 


\section{Box 1. GCF / ADB project in Cambodia: example of Comprehensive Food System Approach}

The GCF and Asian Development Bank funded project in Cambodia demonstrates the full range of food system activities for reducing climate change vulnerability and GHG emissions in agricultural value chains in Cambodia.

This project targets the needs of the most vulnerable populations, including women and rural communities. The project will invest in climate-smart agribusiness value chain infrastructure, capacity strengthening in climate-friendly agriculture, and enabling environment for sound agribusiness policy. It aims to create economic, social, and environmental co-benefits, through increase in yields; improving water use efficiency and energy savings; reduction in post-harvest losses; investing in climate-proof infrastructure to provide more sustainable access to markets; improve household air quality and benefiting productivity while reducing GHG emissions; building capacity of men and women on the use of climate information services and climate-smart agriculture practices along the whole value chain.

The project is aligned with the country's national priorities in climate change adaptation and mitigation and will build on best practices and lessons learned within the country.

There are certainly benefits in improving the productivity of vulnerable farms. However, research also shows that natural capital such as farming land is finite and beyond a certain threshold, it will take more and more resources to produce as soil quality depletes, thus hitting a ceiling on production (Brown 2012). For example, the World Resources Institute estimates a 'land' gap of 593 Mha (described as the difference between projected land area needed for meeting global demand by 2050 and agricultural land area in 2010) if agricultural expansion into forests and savannas is to be avoided (Searchinger et al. 2019). In scenarios where production gains are not made, and consumption patterns are not moderated, agricultural land could expand by about 3.3 billion hectares (Searchinger et al. 2019). Focusing on the food system activities helps sustain benefits beyond production and meet the paradigm criteria of GCF in practice. The example in Box 1 is of a GCF-funded project that takes a food system activity approach to connect farmers across the value chain and strengthen their resilience to climate change and create new income opportunities.

\section{Institutions and governance mechanisms}

In this final level of analysis, we focus on the three linkages of the projects to infrastructure, policy and regulations, and business and industries for uptake and scaling of the projects beyond the project life cycle. Figure 4 shows that nine tenths of the projects make explicit links between food, climate policies, regulations, and relevant policy actors. This high linkage is a result of GCF project guidelines mandating proposals to demonstrate these links under its investment framework, with a specific section dedicated in the proposal template. Infrastructure linkages were also 


\section{Supporting Mechanisms and Institutions}

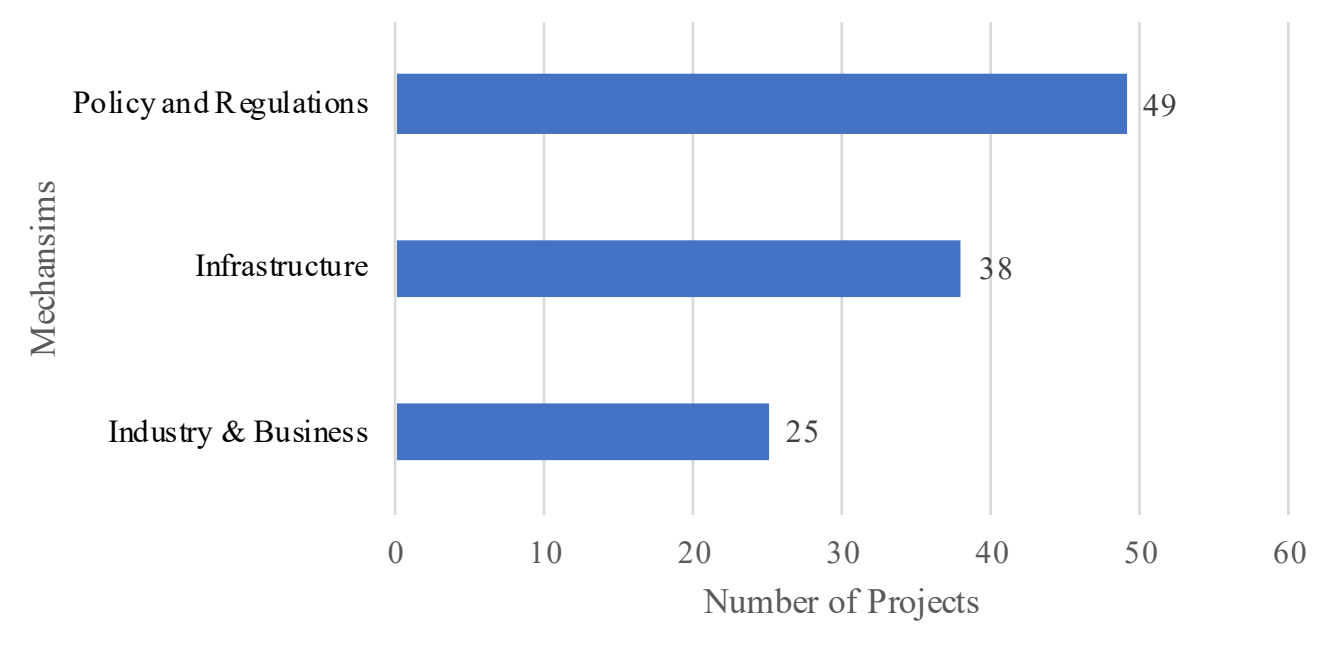

Figure 5. Supporting institutions and governance mechanisms in GCF-funded projects.

prominent as two thirds of projects factored infrastructure investments to support vulnerable communities in areas that generally lacked basic climate and agriculture infrastructure. For example, projects invested in meteorological equipment for accurate weather data or rain harvesting tanks for farmers in drought-prone areas. Investments in such infrastructure were also possible in the projects as over three quarters of GCF projects range upward of US\$10 million and allow capacity for such investments. One important linkage in developing a resilient food system that was lacking in over half of the projects is with industry and business. Industry and business play a crucial role in uptake of the food systems activities beyond farmers. They bring in key investments and are natural partners for building new markets, products, and activities. Historically, however, particularly small and medium-tier businesses lack the financial capital and access to capital needed to make steps towards sustainable transformation. Innovations and transformations in this area therefore require innovative financing and improved linkages across the food system institutional infrastructure. Most projects fell short of identifying such linkages and hence were missing significant support in the food system to make it resilient and sustaining. By focusing on production, projects do not create downstream benefits for the farmers from the value addition in the food by businesses and other actors. Few projects that did focus on all three mechanisms offered a resilient pathway for farmers to benefit from the broader food system activities, and also created a sustaining link with the institutions and governance mechanisms for sustained action. 


\section{Project funding structure and implementation approach}

The GCF classifies the 'health, food, and water security', result under the adaptation theme. Under this theme the impact measure for the projects is on the number of lives impacted. While adaptation efforts are vital to building resilience of the food system and the vulnerable communities dependent on it, it overlooks the significant emissions of GHG by the food system. As discussed earlier, the global food system is responsible for nearly 26 per cent of global GHG emissions. This is a missed opportunity towards a low-carbon and climate-resilient food system. The project developers already have the attention of GCF and by encouraging them towards a cross-cutting approachthat is, projects and programmes that provide actions that may both reduce the amount of GHG and allow vulnerable communities and populations to adapt to climate changeGCF can play a critical role in the transition to a low-carbon and climate-resilient food system.

Our analysis also reveals that GCF funds the majority of the food projects through grants. Grants offer much-needed funding in geographies and interventions that normally lack public and private support. However, the sustainability of the project is questionable once the grants have been consumed. Private and other actors generally have low incentive to participate as they do not find suitable scaling and market opportunities in these projects. By encouraging project developers to take a food system approach, GCF can offer opportunities for actors along the food system to participate in the projects and make these sustaining beyond the grant duration.

We also observed that nearly 80 per cent of the funded food projects are developed and implemented by international organisations. A key reason for this is that international organisations have well-connected networks, experience, and resources at their disposal to design novel projects that meet the GCF guidelines. Much of the knowledge on project design and implementation remains with these international organisations without much coordination with local actors (Chaudhury 2020). This limits the capacity of local organisations to develop robust system-wide projects and take ownership for their challenges. Country ownership is one of the key tenets of GCF funding, yet progress remains slow as seen in only nine projects out of the fifty-six in food developed by national organisations.

\section{Conclusion and way forward}

The major disciplinary and institutional shift to food systems indicates an understanding that our thinking around food and nutrition security, environmental sustainability, and socio-economic outcomes needs to change. This is most effectively 
illustrated by the 2021 UN Food Systems Summit (UNFSS) on delivering progress on the SDGs through tangible changes in the food system. Bringing together a diverse range of people involved in the food systems, the Summit demonstrates the necessity and urgency of delivering transformational change for a just, secure, and sustainable food future.

This analysis on GCF projects and the current literature on food systems and climate finance reveals that, despite a conceptual and institutional shift to food systems thinking, climate financing mechanisms are not fully implementing a systems-oriented approach. The food systems approach allows for a comprehensive engagement with the complex set of activities, diverse range of actors, and drivers affecting these actors across spatial scales. Funding mechanisms are still unduly limited to food production, with a few notable exceptions. This gap means that there is great untapped potential in improving a range of food system outcomes in the spheres of environment, socio-economics, and food and nutrition security.

To move forward, it is critical to recognise the current limitations of programmatic, short-term, and siloed funding mechanisms. While the thinking around resilient, systematic, and paradigm-shifting change is being incorporated into climate finance, as this analysis demonstrates, interventions are fragmented and seldom address a systems perspective. This means that the gains made in specific areas of the food system are being limited by the fact that complementary interventions are not made elsewhere. It is therefore recommended that climate financing projects take a longterm, food systems perspective in planning and implementing interventions. Given the lack of data and information that often exists in such fields, this necessitates equipping financiers, project developers, and funding reviewers with the data and risk tools needed to evaluate appropriately, projects developed through a systems thinking lens. Incorporating systems learning throughout funding mechanisms will ensure an even shift in financing and project-funding mindsets.

Collaboration and match-making tools that allow project developers to create necessary stakeholder engagements needed for a systems perspective can facilitate transition to more systems-oriented climate financing that is grounded in local and national contexts. Working alongside bodies like the CGIAR Research Program on Climate Change, Agriculture And Food Security (CCAFS) in their efforts to catalyse and diversify climate financing, while using the momentum built from the UNFSS will ensure that innovative financing solutions are systems oriented from the beginning of the process, instead of being an afterthought. Finally, the analysis demonstrates the strength of interdisciplinary project development. Interdisciplinarity in delivering interventions focused on achieving the SDGs must be supported across the financing and implementation process. This approach is important and timely as institutions at different scales are exploring opportunities for national governments and other actors, 
to move beyond food production to building a low-carbon and climate-resilient food system future through different and innovative intervention pathways.

\section{Acknowledgments}

This research was conducted under the British Academy Postdoctoral Fellowship programme awarded to the first author. We would like to thank Carolina Douek for her editorial assistance. The paper has also greatly benefited from the constructive comments of the two anonymous journal reviewers.

\section{References}

Brown, L.R. (2012), Full Planet, Empty Plates: The New Geopolitics of Food Scarcity (New York, WW Norton).

Brunori, G., Bartolini, F., Avermaete, T., Brzezina, N., Mathijs, E., Marsden, T., Moragues Faus, A. \& Sonnino, R. (2015), 'Transmango Project-Assessment of the Impact of Global Drivers of Change on Europe's Food And Nutrition Security (FNS)'. transmango.wordpress.com/output

Cabrera, D., Colosi, L. \& Lobdell, C. (2008), 'Systems Thinking', Evaluation and Program Planning, 31: 299-310. https://doi.org/10.1016/j.evalprogplan.2007.12.001

Castaneda, R., Doan, D., Newhouse, D.L., Nguyen, M., Uematsu, H. \& Azevedo, J.P. (2016), 'Who are the Poor in the Developing World?', World Bank Policy Research Working Paper 7844. https://doi.org/10.1596/1813-9450-7844

CFS (Committee on World Food Security) (2016), 'Connecting Smallholders to Markets', CFS 43 (Rome, Food and Agriculture Organization (FAO)).

Chaudhury, A. (2020), 'Role of Intermediaries in Shaping Climate Finance in Developing CountriesLessons from the Green Climate Fund', Sustainability, 12: 5507. https://doi.org/10.3390/su12145507

Chaudhury, A.S., Helfgott, A., Thornton, T.F. \& Sova, C. (2016), 'Participatory Adaptation Planning and Costing: Applications in Agricultural Adaptation in western Kenya', Mitigation and Adaptation Strategies for Global Change, 21: 301-22. https://doi.org/10.1007/s11027-014-9600-5

Chaudhury, A.S., Thornton, T.F., Helfgott, A., Ventresca, M.J. \& Sova, C. (2017), 'Ties that Bind: Local Networks, Communities and Adaptive Capacity in Rural Ghana', Journal of Rural Studies, 53: 214-28. https://doi.org/10.1016/j.jrurstud.2017.05.010

Chiriac, D., Naran, B. \& Falconer, A. (2020), 'Examining the Climate Finance Gap for Small-scale Agriculture', Climate Policy Initiative. https://www.climatepolicyinitiative.org/publication/climate-finance-small-scale-agriculture/

CIAT (International Centre for Tropical Agriculture) (2017), 'Sustainable Food Systems'. https://ciat.cgiar.org/about/strategy/sustainable-food-systems/ [accessed 1 July 2021].

Conevska, A., Ford, J., Lesnikowski, A. \& Harper, S. (2019), 'Adaptation Financing for Projects Focused on Food Systems through the UNFCCC', Climate Policy, 19: 43-58. https://doi.org/10.1080/14693062.2018.1466682

Diaz-Bonilla, E. (2018), 'Financing “a Sustainable Food Future”: Some Thoughts for the G20', Economics Discussion Papers. https://www.g20-insights.org/policy_briefs/financing-a-sustainable-food-future/ 
Dillemuth, A. \& Hodgson, K. (2016), 'Food Aggregation, Processing, and Distribution', Planning \& Policy Briefs. Growing Food Connections. http://growingfoodconnections.org/wp-content/ uploads/sites/3/2015/11/GFCFoodInfrastructurePlanningPolicyBrief_2016Sep22-3.pdf

Etzion, D., Gehman, J., Ferraro, F. \& Avidan, M. (2017), 'Unleashing Sustainability Transformations through Robust Action', Journal of Cleaner Production, 140(P1): 167-78. https://doi.org/10.1016/j.jclepro.2015.06.064

FAO (Food and Agriculture Organization of the United Nations) (2012), The State of Food and Agriculture-Investing in Agriculture for a Better Future (Rome, FAO).

FAO (Food and Agriculture Organization of the United Nations) (2021), 'Boosting Smallholder Resilience for Recovery: Boosting the Resilience of Smallholders for COVID-19 Recovery' (Santiago, FAO COVID-19 Response and Recovery Programme: Latin America and the Caribbean). https://doi.org/10.4060/cb2045en

GCF (Green Climate Fund) (2020), 'Initial Investment Framework' (Songdo, Incheon, Republic of Korea, Green Climate Fund). https://www.greenclimate.fund/document/initial-investment-framework

GFS (Global Food Security) (2020), 'Resilience of the UK Food System in a Global Context (GFSFSR)'. https://www.foodsecurity.ac.uk/research/food-system-resilience/

Gneiting, U. \& Sonenshine, J. (2018), 'A Living Income for Small-scale Farmers: Tackling Unequal Risks and Market Power', Oxfam Discussion Papers. https://policy-practice.oxfam.org/ resources/a-living-income-for-small-scale-farmers-tackling-unequal-risks-and-marketpower-620596/; https://doi.org/10.21201/2018.3606

Hasnain, S., Ingram, J. \& Zurek, M. (2020), 'Mapping the UK Food System-A Report for the UKRI Transforming UK Food Systems Programme' (Oxford, Environmental Change Institute, University of Oxford).

https://www.eci.ox.ac.uk/research/food/downloads/Mapping-the-UK-food-system-digital.pdf

Hazell, P. B., Pomareda, C. \& Valdés, A. (1986), Crop Insurance for Agricultural Development: Issues and Experience (Baltimore, MD, Johns Hopkins University Press).

HLPE (2017), 'Nutrition and Food Systems. A Report by the High Level Panel of Experts on Food Security and Nutrition of the Committee on World Food Security' (Rome, Food and Agriculture Organization). https://www.fao.org/3/i7846e/i7846e.pdf

IFAD (International Fund for Agricultural Development) (2013), 'Smallholders, Food Security and the Environment' (Rome, International Fund for Agricultural Development and United Nations Environment Programme). https://www.ifad.org/documents/38714170/39135645/smallholders_ report.pdf/133e8903-0204-4e7d-a780-bca847933f2e

Ingram, J. (2011), 'A Food Systems Approach to Researching Food Security and its Interactions with Global Environmental Change', Food Security, 3: 417-31. https://doi.org/10.1007/s12571-011-0149-9

Ingram, J. \& Zurek, M. (2018), 'Food Systems Approaches for the Future', in Agriculture \& Food Systems to 2050: Global Trends, Challenges and Opportunities (Singapore, World Scientific), Chapter 16. https://doi.org/10.1142/9789813278356_0016

Johnson, R.B., Onwuegbuzie, A.J. \& Turner, L.A. (2007), 'Toward a Definition of Mixed Methods Research', Journal of Mixed Methods Research, 1: 112-33. https://doi.org/10.1177/1558689806298224

King, G., Keohane, R.O. \& Verba, S. (1994), Designing Social Inquiry: Scientific Inference in Qualitative Research (Princetopn, NJ, Princeton University Press). https://doi.org/10.1515/9781400821211

Kwak, J. (2020), 'The End of Small Business. Giant Corporations May Be the Only Survivors in the Post-Pandemic Economy', The Washington Post, 9 July. https://www.washingtonpost.com/ outlook/2020/07/09/after-covid-19-giant-corporations-chains-may-be-only-ones-left/ 
Lang, T., \& Barling, D. (2012), 'Food Security and Food Sustainability: Reformulating the Debate', The Geographical Journal, 178(4), 313-26. http://www.jstor.org/stable/23360870; https://doi.org/10.1111/j.1475-4959.2012.00480.x

Lazarus, R.J. (2008), 'Super Wicked Problems and Climate Change: Restraining the Present to Liberate the Future', Cornell Law Review, 94: 1153.

Marchant-Forde, J.N. \& Boyle, L.A. (2020), 'COVID-19 Effects on Livestock Production: A One Welfare Issue', Frontiers in Veterinary Science, 7: 734. https://www.frontiersin.org/articles/10.3389/fvets.2020.585787/full; https://doi.org/10.3389/fvets.2020.585787

Mbow, C. et al. (2019), 'Food Security', in Climate Change and Land: An IPCC Special Report on Climate Change, Desertification, Land Degradation, Sustainable Land Management, Food Security, and Greenhouse Gas Fluxes in Terrestrial Ecosystems (Geneva, Intergovernmental Panel on Climate Change (IPCC)). https://www.ipcc.ch/site/assets/uploads/sites/4/2019/11/08_Chapter-5. pdf.

Meadows, D.H. (2008), Thinking in Systems: A Primer (Hartford, VT, Chelsea Green Publishing). Millan, A., Limketkai, B. \& Guarnaschelli, S. (2019), 'Financing the Transformation of Food Systems Under a Changing Climate', CGIAR Research Program on Climate Change, Agriculture and Food Security (CCAFS), Wageningen. https://cgspace.cgiar.org/bitstream/handle/10568/101132/ CCAFS $\% 20$ KOIS $\% 20$ Financing $\% 20$ the $\% 20$ Transformation $\% 20$ of $\% 20$ Food $\% 20$ Systems $\% 20$ Under $\% 20 \mathrm{a} \% 20$ Changing $\% 20$ Climate.pdf

Nakhooda, S., Norman, M., Barnard, S., Watson, C., Greenhill, R., Caravani, A. \& Banton, G. (2014), 'Climate Finance: Is it Making a Difference? A Review of the Effectiveness of the Multilateral Climate Funds' (London, Overseas Development Institute). https://cdn.odi.org/media/documents/9359.pdf

National Statistics (2019), 'Food Statistics in your Pocket: Summary', Department of Environment, Food and Rural Affairs. https://www.gov.uk/government/statistics/food-statistics-pocketbook/ food-statistics-in-your-pocket-summary\#agri-food-sector-employees-gb-q4-2019

Nghiem, L., Läderach, P., Talsma, T., Weatherhead, M., Pacillo, G., Wheatley, C., Charlot, C. \& Imbach, P. (2018), 'The Business Advantage: Mobilizing Private Sector-led Climate Actions in Agriculture', The International Fund for Agricultural Development (IFAD), CGIAR and the International Centre for Tropical Agriculture (CIAT). https://www.ifad.org/documents/ 38714170/40321194/business_advantage.pdf/c33367a8-f689-41ae-8b7f-976364bb0c01

Palmer, N. (2016), 'Making Climate Finance Work in Agriculture', World Bank Discussion Paper. https://openknowledge.worldbank.org/bitstream/handle/10986/25366/ACS19080-REVISEDOUO-9-Making-Climate-Finance-Work-in-Agriculture-Final-Version.pdf?sequence $=1 \&$ is Allowed=y

Parsons, K., Hawkes, C. \& Well, R., (2019), 'Brief 2: What is the Food System? A Food Policy Perspective', Rethinking Food Policy: A Fresh Approach to Policy and Practice (London, Centre for Food Policy).

Poore, J. \& Nemecek, T. (2018), 'Reducing Food's Environmental Impacts through Producers and Consumers', Science, 360: 987-92. https://doi.org/10.1126/science.aaq0216

Saldaña, J. (2021), The Coding Manual for Qualitative Researchers, 4th edn (London, SAGE).

Searchinger, T., Waite, R., Hanson, C., Ranganathan, J., Dumas, P., Matthews, E. \& Klirs, C. (2019), 'Creating a Sustainable Food Future: A Menu of Solutions to Feed Nearly 10 Billion People by 2050', final report, World Resource Institute. https://research.wri.org/sites/default/files/2019-07/WRR_Food_Full_Report_0.pdf

Silverman, D. (2005), Doing Qualitative Research: A Practical Handbook (London, SAGE). 
Smith, E., Mcinroy, G., Smith, P., D’angelo, C., Knack, A. \& Bertscher, A. (2019), 'Insights into Global Food System Risks and Opportunities and their Implications for the FSA' (Santa Monica, CA, RAND Corporation). https://www.rand.org/pubs/research_reports/RR2830.html; https://doi.org/10.7249/RR2830

Springfield Centre (2015), 'The Operational Guide for Making Markets Work for the Poor (M4P) Approach', 2nd edn funded by Swiss Agency for Development and Cooperation (SDC) and the UK Department for International Development (DFID). https://www.enterprise-development.org/wp-content/uploads/m4pguide2015.pdf

Stephens, E. C., Martin, G., Van Wijk, M., Timsina, J. \& Snow, V. (2020), 'Impacts of COVID-19 on Agricultural and Food Systems Worldwide and on Progress to the Sustainable Development Goals', Agricultural Systems, 183: 102873. https://doi.org/10.1016/j.agsy.2020.102873

Townsend, R., Benfica, R.M., Prasann, A., Lee, M. \& Shah, P. (2017), 'Future of Food: Shaping the Food System to Deliver Jobs' (Washington, DC, World Bank). https://openknowledge.worldbank.org/bitstream/handle/10986/26506/114394-WP-PUBLIC-18-4-2017-10-56-45-ShapingtheFoodSystemtoDeliverJobs.pdf?sequence $=1 \&$ isAllowed $=\mathrm{y}$

UNCTAD (United Nations Conference on Trade and Development) (2020), 'Impact of the COVID-19 Pandemic on Trade and Development: Transitioning to a New Normal' (New York, United Nations). https://unctad.org/system/files/official-document/osg2020d1_en.pdf

UNEP (United Nations Environment Programme ) (2016), 'The Adaptation Finance Gap Report 2016' (Nairobi, UNEP). https://unepdtu.org/publications/the-adaptation-finance-gap-report/

UNFCCC (United Nations Framework Convention on Climate Change) (2021), 'Nationally Determined Contributions under the Paris Agreement', Synthesis Report by the Secretariat. https://unfccc.int/documents/306848.

Van Berkum, S., Dengerink, J. \& Ruben, R. (2018), 'The Food Systems Approach: Sustainable Solutions for a Sufficient Supply of Healthy Food', Wageningen Economic Research Memorandum 2018-064, Wageningen University. https://doi.org/10.18174/451505

Woodhill, J., Hasnain, S. \& Griffith, A. (2020), 'Farmers and Food Systems: What Future for Smallscale Agriculture' (Oxford, Environmental Change Institute, University of Oxford). https://www.eci.ox.ac.uk/research/food/downloads/Farming-food-WEB.pdf

World Bank (2021), 'World Bank Group Climate Change Action Plan 2021-2025: Supporting Green, Resilient, and Inclusive Development' (Washington, DC, World Bank). https://openknowledge. worldbank.org/bitstream/handle/10986/35799/CCAP-2021-25.pdf?sequence=2\&isAllowed=y

WRAP (2020), 'Food Waste Reduction Roadmap'. https://wrap.org.uk/resources/guide/waste-prevention-activities/food

WWF (Worldwide Fund for Nature) (2021) 'Driven to Waste: Global Food Loss on Farms'. https:// wwfint.awsassets.panda.org/downloads/wwf_uk_driven_to_waste_the_global_impact_of_ food_loss_and_waste_on_farms.pdf

Zurek, M. et al. (2018), 'Assessing Sustainable Food and Nutrition Security of the EU Food SystemAn Integrated Approach', Sustainability, 10: 4271.

https://doi.org/10.3390/su10114271

\section{Notes on the authors}

Dr Abrar Chaudhury is a Research Fellow and British Academy Postdoctoral Fellow at Said Business School researching on topics of global environmental change, climate finance, policy implementation, sustainable development, and corporate purpose. He is affiliated with Oxford's Environmental Change Institute and Green Templeton College. Abrar is a global professional with over twenty years of experience in technology, consulting, and research contexts across continents and sectors. Under the British Academy Postdoctoral Fellowship, he is 
investigating the ways in which dedicated climate funding, such as the Green Climate Fund, and emerging technologies shape implementation and diffusion of climate action in emerging economies.

Recent publications include:

Chaudhury, A. (2020), 'Role of Intermediaries in Shaping Climate Finance in Developing CountriesLessons from the Green Climate Fund', Sustainability, 12: 5507. https://doi.org/10.3390/su12145507

Chaudhury, A., Thornton, T.F., Helfgott, A. \& Sova, C. (2017), 'Applying the Robust Adaptation Planning (RAP) Framework to Ghana's Agricultural Climate Change Adaptation Regime', Sustainability Science, 12: 657-76. https://doi.org/10.1007/s11625-017-0462-0

Chaudhury, A., Thornton, T.F., Ventresca, M., Helfgott, A. \& Sova, C. (2017), 'Ties that Bind: Local Networks, Communities and Adaptive Capacity in Rural Ghana', Journal of Rural Studies, 53: 214-28. https://doi.org/10.1016/j.jrurstud.2017.05.010

https://orcid.org/0000-0002-3094-7639

abrar.chaudhury@sbs.ox.ac.uk

Dr Saher Hasnain is a Postdoctoral Researcher based at the Environmental Change Institute's Food Systems Transformations Group at the University of Oxford. She is engaged in a number of projects focused on developing mechanisms to better understand and synthesise key trends and possible futures in global food systems and to support informed and strategic decision making between food systems stakeholders.

Recent publications include:

Hasnain, S., Ingram, J. \& Zurek, M. (2020), 'Mapping the UK Food System-A Report for the UKRI Transforming UK Food Systems Programme' (Oxford, Environmental Change Institute, University of Oxford).

https://www.eci.ox.ac.uk/research/food/downloads/Mapping-the-UK-food-system-digital.pdf Hasnain, S. (2019), 'Disruptions and Food Consumption in Islamabad', Geoforum, 108: 49-58. https://doi.org/10.1016/j.geoforum.2019.11.017

https://orcid.org/0000-0001-5072-0776

To cite the article: Abrar Chaudhury and Saher Hasnain (2021), 'Financing food system transformation: insights from global climate projects', Journal of the British Academy, 9(s10): 21-42.

DOI https://doi.org/10.5871/jba/009s 10.021

Journal of the British Academy (ISSN 2052-7217) is published by

The British Academy, 10-11 Carlton House Terrace, London, SW1Y 5AH

www.thebritishacademy.ac.uk 